\title{
Erectile dysfunction and mood disorders in patients undergoing cardiac rehabilitation
}

\author{
DOI: https://doi.org/10.5114/pq.2020.95774
}

\author{
Sandra Jóźwik', Magdalena Sierakowska', Robert Gajda², Joanna Szczepańska-Gieracha ${ }^{1}$ \\ ${ }^{1}$ Department of Physiotherapy, University School of Physical Education in Wrocław, Wrocław, Poland \\ ${ }^{2}$ Centre for Sports Cardiology, Gajda-Med Medical Centre, Pułtusk, Poland
}

\section{Abstract}

Introduction. Mood disorders, a predominant symptom of depression, are correlated with the risk of cardiovascular disease (CVD) development and unfavourable course. Anxiety that accompanies CVD is concurrently its cause, consequence, and debilitating factor. There is also a correlation between CVD and erectile dysfunction (ED). The purpose of this study was to investigate the relationship between mood disorders and ED in men undergoing cardiac rehabilitation and determine the role of diabetes and other risk factors in both health problems.

Methods. The study involved 69 men aged 32-79 admitted to cardiac rehabilitation procedure. Beck Depression Inventory served to measure mood disorders, and International Index of Erectile Function 5 to establish sexual dysfunction. A survey pertaining social, demographic, and clinical data was conducted among the participants.

Results. Overall, $85.5 \%$ of the participants were overweight or obese. Over half of them suffered from hypertension or lipid disorders. About a third had diabetes, $77 \%$ smoked cigarettes. Mood disorders were found in 5 men, ED among $74 \%$ of the participants. There was no statistically significant correlation between mood disorders and diabetes, smoking, or excess body mass. ED prevalence showed no correlation with overweight or mood disorders. The only statistically significant risk factor for ED was diabetes.

Conclusions. The results do not reveal a connection between mood disorders and ED in the studied sample. It is impossible to measure shared risk factors for both disorders in a group with only 5 people presenting depression symptoms. Diabetes significantly influences ED prevalence among men with coronary artery disease.

Key words: coronary artery disease, DEC syndrome, cardiac rehabilitation, erectile dysfunction, depression, diabetes

\section{Introduction}

According to the World Health Organization, cardiovascular diseases (CVD) are a leading cause of death and disability in the world. Statistics Poland estimates that considering the current increase in the prevalence of the disease and ageing of the Polish population, the number of deaths caused by CVD will amount to 200000 in 2020 [1, 2]. Growing mortality rate could be effectively prevented through the elimination of risk factors such as poor diet, insufficient physical activity, tobacco smoking, obesity, and alcohol abuse.

In recent years, the approach to treating CVD has changed and a greater focus is being put on the patient's life quality to improve not only survival, but also the person's well-being. In this context, complex cardiac rehabilitation consists of physical training, psychological help, and secondary prevention of CVD. The crucial goal of cardiac rehabilitation is to decrease mortality and disease progression among patients with CVD, but it also includes disability prevention, as well as improvement of the psychophysical condition and the quality of life [3].

The quality of life as a term was introduced by Schipper in 1990 [4], defined as an 'operational effect of the disease and its treatment, subjectively or objectively perceived by the patient'. The evaluation of specific parameters of the quality of life allows to improve communication with the patient from their point of view and constitutes the key to the treatment of psychosocial conditions [5, 6].

Depression and anxiety disorders are among the crucial factors interfering with the positive outcomes of rehabilitation [7]. Mood disorders, a dominant symptom of depression, are correlated with the risk of CVD development and its negative outcomes, including cardiac arrest [7]. It has also been proven that in patients treated for coronary artery disease, there is a higher prevalence of depressive disorders compared with the general population [8]. In 1993, Frasure-Smith et al. [9] were the first to identify post-cardiac arrest depression as an important factor of 3-4-time increase of mortality after a cardiac incident, irrelevant of earlier cardiac arrests or other CVD. Patients with depression have an even 5 times greater odds of experiencing a severe coronary artery episode ending with death compared with the general population. The prevalence of depression in the general population amounts to $5 \%$, with $17-20 \%$ among patients with ischaemic heart disease, and as much as $16-28 \%$ among those who experienced a cardiac arrest $[10,11]$.

CVDs, including cardiac arrest, are a strong stress-inducing factor owing to their sudden onset and deprivation of many psychological needs, such as respect, safety, or acceptance. Cardiac arrest is an event significantly influencing the life of the diseased person, as well as their family. There is uncertainty, helplessness, and frustration that come from having to accept the reality of the new situation. Thus, it is not only the cardiac treatment, but also a psychological observation of the patient that need to be introduced because there is a danger that anxiety and depressive states will persist and worsen [6].

Long-term stress can also be a factor promoting ischaemia of the heart, can disrupt the heart rate and decrease the heart

Correspondence address: Sandra Jóźwik, Department of Physiotherapy, University School of Physical Education in Wrocław, al. I.J. Paderewskiego 35, 51-612 Wrocław, Poland, e-mail: j_sandra@wp.pl 
efficiency. The persistent secretion of stress hormones, especially cortisol, has a negative impact on the whole body, including the circulatory system. The result is hypertension, increased heart rate, and increased platelet aggregation [12]. Many patients with depression during the disease have no motivation to change their lifestyle towards a more healthpromoting approach, do not stop smoking, do not care for the diet, and avoid physical activity, which worsens the situation and obviously leads to further degradation of their health condition.

Stress results in a continuous, chronic stimulation of the sympathetic nervous system. This is related to both the increased mortality of cardiac patients and the presence and severity of erectile dysfunction (ED) symptoms [13]. Therefore, the heart rate recovery provides us with very important information. It reflects the activity of the parasympathetic part of the autonomic nervous system, and thus the body's ability to achieve the state of balance after intense physical exertion. Kałka et al. [13] showed that this was not only a marker used for assessing the risk of sudden cardiac death - its value also significantly correlated with the presence of ED. Therefore, according to the author, physical training is an absolute must in the treatment of heart disease. It supports the parasympathetic part of the autonomic nervous system, reduces the risk of sudden cardiac death, positively affects the quality of erections and sexual performance, and also increases the secretion of endorphins, which improves the patient's mood and well-being [13].

Szczepańska-Gieracha et al. [14] revealed that mood disorders had a key impact on the subjective evaluation of the quality of life, the perception of one's own health, and the course of treatment. Thus, psychotherapy should play an important role in cardiac rehabilitation, focusing on reducing negative emotions such as anxiety, depression, and anger, creating a positive attitude towards the situation, work, life goals, and a change in 'life philosophy,' encouraging a lifestyle with active fight against the factors promoting the disease relapse [15].

Anxiety might be present as part of depressive and anxiety disorders or as a standalone symptom. In both cases, it negatively impacts on the process of cardiac rehabilitation, as well as treatment as a whole [10]. It is a negative emotional state connected with a persistent feeling of threat, fear for one's own health or the loved ones, fear about the situation at work, etc. The anxiety present in cardiac diseases is a causal and debilitating factor at the same time [16]. Anxiety also occurs during dyspnoea or arrhythmia, increases the feeling of discomfort and unease, and can even result in panic attacks. Anxiety leads to $2.5-5$ times greater risk of returning ischaemia, another cardiac arrest, ventricular fibrillation, and even a sudden cardiac death [14, 17]. Studies have shown that in the group of patients with a panic disorder, mortality is twice as high as in the group without the disorder [17].

Patients who cannot cope with their anxiety and depression often retire from the society and avoid physical activity. The term 'kinesiophobia' is more and more often described in literature with reference to an abnormal fear of physical activity due to disease relapse concerns. For that reason, patients in whom mood or anxiety disorders were diagnosed are advised to undergo cardiac rehabilitation defined as a complex set of actions mandatory to altering the causes lying at the root of the disease. This creates the best possible physical, social, and mental conditions facilitating the patients' return to normal functioning in the society [7].

Another important factor influencing the quality of life of patients treated for CVD is ED, defined as an inability to achieve erection sufficient for a satisfactory sexual intercourse [18]. Until 1980s, ED was assumed to be a psychological issue. Nowadays, much evidence exists that ED has also physiological causes, mostly cardiovascular, neurological, or hormonal [18]. A study by Lew-Starowicz performed in 2005 revealed that 1.5 million of Poles suffered from some form of ED, and that the problem was observed more often in patients with a CVD or risk factors including diabetes, tobacco smoking, or chronic obstructive pulmonary disease [19].

ED is also frequently associated with taking medications for CVD [20]. According to pharmaco-epidemiological studies, as many as $25 \%$ of ED cases are caused by drugs (primarily anti-hypertensives and diuretics) whose mechanisms of action disrupt the processes responsible for erection. Therefore, in cardiac patients complaining about sexual problems, physicians should consider changing the drug or lowering the dose of the ED-inducing medication [21].

Decreased sexual activity and ED among cardiac patients are also related to anxiety and depression [3]. Studies by Izdebski [22] performed among people aged 50 or more show that sexual disorders can have a negative impact on the relationship with a partner and the patient's self esteem, both affecting the quality of life. Kałka et al. [18] demonstrated that $82 \%$ of patients with cardiac insufficiency maintained that sexual capacity defined as being able to have a satisfying sexual activity was important or very important.

One should not forget about the natural passage of time and the biological factors affecting sexual performance. Epidemiological data on ED in the US regarding men aged $40-70$ show that ED problems were found in as many as $52 \%$ of respondents and their frequency strongly correlated with age. Hormonal disorders, progressive testosterone deficiency (andropause), and chronic diseases are closely related to ED [23]. Among older men, many penile pathologies occur as a result of ageing. There is a decrease in collagen and elastic fibres in the whitish membrane and a decrease in smooth muscles; these phanomena are associated with chronic ischaemic changes in the microcirculation [24].

Problems in the sexual sphere are a cause of mental discomfort and self-esteem disorders; they can result in gradual withdrawal from social activity, isolation, as well as depression [25]. Older men should be thoroughly diagnosed, as depression leads to suicide in this age group 3 times more often [25]. Therefore, sexual disorders in men become an integral part of cardiac diseases and should be treated as such. One of the elements that determine the quality of life is a successful sex life, which plays a role in multiple aspects of human behaviour. For that reason, when speaking of cardiac rehabilitation, it is vital not to neglect this important aspect of quality of life.

\section{Study aim}

The aim of the study was to evaluate the relationship between mood disorders and ED in men undergoing cardiac rehabilitation, to analyse the risk factors for both health issues, and to answer the following questions:

1. Are there any relationships between mood disorders and ED in patients undergoing cardiac rehabilitation?

2. Are there any significant differences between the groups of patients with and without mood disorders in terms of such factors as ED, obesity, tobacco smoking, diabetes?

3. Are there any significant differences between patients with and without ED in regard to such factors as presence of mood disorders, obesity, tobacco smoking, diabetes?

4. Do these 2 disorders have any shared risk factors? 


\section{Subjects and methods}

Patients

The study was conducted in a cardiology centre running the second stage of cardiac rehabilitation in outpatient conditions. The study group consisted of 69 men aged 32-79 years (mean age: 60.9 years, $S D: 8.9$ ). The average values of height and body mass are collected in Table 1. The mean body mass index (BMI) exceeded $25 \mathrm{~kg} / \mathrm{m}^{2}$, which indicates frequent overweight cases in the study group; $62 \%$ of the subjects were overweight, and $23 \%$ were diagnosed as obese. Almost half of the men (46\%) declared secondary education, $32 \%$ reported higher education, and $22 \%$ had vocational education. Overall, $77 \%$ of the group were active smokers. More than a half suffered from hypertension or lipid disorders. Around $1 / 3$ of the subjects suffered from diabetes (Table 2 ).

\section{Methods}

Beck Depression Inventory (BDI), developed in 1961 by Beck, was used to measure the severity of mood disorders and depressive symptoms. It consists of 21 questions. The patient chooses one answer to each question, taking into consideration their mood and well-being over the previous 7 days. Measures of $0-10$ indicate no mood disorders, the range of 11-27 points at mild to moderate mood disorders, and scores over 27 imply severe mood disorders. BDI has also a somatic subscale, referring to the somatic symptoms of depression (eating disorders, sleeping disorders, constant tiredness and fatigue, etc.), and an emotional subscale, referring to problems connected with mood, motivation, and self-esteem. BDI is a screening tool for assessing mood disorders, and its results are an indication for further diagnostic process, not a clinical diagnosis per se [26]. The International Index of Erectile Function 5 (IIEF-5) was applied to evaluate ED. The questionnaire consists of 5 questions and the answers are provided on a 5-point Likert scale. The result indicates the presence and severity of ED over the previous 6 months [27]. A score lower than 21 points may denote the presence of ED.

The last assessment tool used in the current study was a questionnaire aiming to collect information on the patient's life, everyday functioning, as well as awareness of heart disease prevention and course. A set of questions referred to selected CVD risk factors, such as hypertension, lipid disorders, obesity, and diabetes. The questionnaire also included items that concerned smoking (the habit duration, the number of cigarettes smoked daily, and maintaining smoking in the treatment period), as well as questions about previous prevalence of ED and medications supporting erection, i.e. Viagra, Levitra, Cialis, and over-the-counter drugs like Braveran or Penigra.

\section{Statistical analysis}

The analytical description of the material included determining mean values, standard deviations, and the range of variability of the studied parameters for continuous variables. In the case of categorized characteristics, the data were given in numbers and percentages. Correlations between continuous variables were assessed by determining the Pearson correlation coefficient. For categorized characteristics, chisquare test of independence was applied. The comparable analysis of the subgroups with and without the dysfunctions was performed with the use of Student's $t$-test for independent samples. The statistical significance was set at $p<0.05$.

\section{Ethical approval}

In accordance with the latest guidelines of the Working Group on Cardiac Rehabilitation and Exercise Physiology of the Polish Cardiac Society, each cardiac patient should be provided with comprehensive cardiac rehabilitation. Comprehensiveness consists not only in improving the patient's fitness, combating risk factors, or modifying lifestyle; it also takes into account the sexual needs of patients. This is an important element of their lives, given that any disorder in the sphere of sexual performance can lead to depressive episodes and restrictions of functioning in the society as a consequence of the disease. The presented study conducted among cardiac patients did not receive any consent of an ethical committee because it was carried out as part of the comprehensive cardiac rehabilitation process as a standard procedure to determine the severity of the problem among rehabilitated patients. Therefore, no ethical committee approval seemed necessary.

\section{Informed consent}

Informed consent has been obtained from all individuals included in this study.

\section{Results}

The parameters regarding the patients' height, weight, body mass, and coexisting diseases are presented in Tables 1 and 2. More than half of the patients had hypertension and lipid disorders; $30 \%$ of the men surveyed suffered from diabetes (Table 2).

Mood disorders were diagnosed in 5 patients, which was $7.2 \%$ of the studied group. ED was reported by 51 men, which constituted $73.9 \%$ of the studied group. There was no significant relationship between ED and mood disorders among the investigated men (Table 3).

There were no statistically significant differences between depressed and non-depressed patients in terms of BMI or IIEF-5 score (Table 4).

Table 1. Distribution of the basic somatic parameters

\begin{tabular}{|l|r|r|c|c|}
\hline \multirow{2}{*}{ Parameter } & \multirow{2}{*}{ Mean } & \multirow{2}{*}{ SD } & \multicolumn{2}{|c|}{ Range of variation } \\
\cline { 4 - 5 } & & & Minimum & Maximum \\
\hline Body height $(\mathrm{cm})$ & 174.3 & 5.9 & 160.0 & 185.0 \\
\hline Body weight $(\mathrm{kg})$ & 85.6 & 11.1 & 63.0 & 112.0 \\
\hline BMI $\left(\mathrm{kg} / \mathrm{m}^{2}\right)$ & 28.1 & 3.1 & 22.6 & 37.3 \\
\hline
\end{tabular}

$\mathrm{BMI}$ - body mass index

Table 2. Comorbidities occurring in the studied group

\begin{tabular}{|l|c|c|}
\hline Disease & $n$ & $\%$ \\
\hline Hypertension & 41 & 59.4 \\
\hline Lipid disorders & 44 & 63.8 \\
\hline Diabetes & 21 & 30.4 \\
\hline
\end{tabular}

Table 3. Erectile dysfunction and mood disorders in the studied group of men (in numbers)

\begin{tabular}{|c|c|c|c|c|c|}
\cline { 3 - 6 } \multicolumn{2}{c|}{} & \multicolumn{2}{|c|}{ Erectile dysfunction } & \multicolumn{2}{c|}{ Chi-square test } \\
\cline { 3 - 6 } \multicolumn{2}{c|}{} & No & Yes & $\chi^{2}$ & $p$ \\
\hline \multirow{2}{*}{ Mood disorders } & No & 17 & 47 & \multirow{2}{*}{0.104} & 0.748 \\
\cline { 2 - 5 } & Yes & 1 & 4 & & \\
\hline
\end{tabular}


Table 4. Differences between the groups of patients with and without mood disorders

\begin{tabular}{|c|c|c|c|c|c|}
\hline \multirow{2}{*}{ Parameter } & \multirow{2}{*}{$\begin{array}{c}\text { Distribution } \\
\text { parameter }\end{array}$} & \multicolumn{2}{|c|}{ Mood disorders } & \multicolumn{2}{|c|}{ Student's test } \\
\hline & & No & Yes & $t$ & $p$ \\
\hline \multirow{2}{*}{$\begin{array}{l}\text { BMI } \\
\left(\mathrm{kg} / \mathrm{m}^{2}\right)\end{array}$} & Mean & 28.2 & 26.9 & \multirow{2}{*}{0.947} & \multirow{2}{*}{0.347} \\
\hline & $S D$ & 3.2 & 2.0 & & \\
\hline \multirow{2}{*}{$\begin{array}{l}\text { IIEF-5 } \\
\text { (score) }\end{array}$} & Mean & 15.8 & 12.4 & \multirow{2}{*}{1.201} & \multirow{2}{*}{0.234} \\
\hline & $S D$ & 6.0 & 6.9 & & \\
\hline
\end{tabular}

$\mathrm{BMI}$ - body mass index, IIEF-5 - International Index of Erectile Function 5

Table 5. Comparison of groups of patients with different risk factors with regard to the presence of depressive symptoms

\begin{tabular}{|c|c|c|c|c|c|}
\hline \multirow{2}{*}{ Risk factor } & \multirow{2}{*}{ Prevalence } & \multicolumn{2}{|c|}{ Mood disorders } & \multicolumn{2}{|c|}{ Chi-square test } \\
\hline & & Yes & No & $\chi^{2}$ & $p$ \\
\hline \multirow{2}{*}{ Diabetes } & Yes & 2 & 19 & \multirow{2}{*}{0.233} & \multirow{2}{*}{0.629} \\
\hline & No & 3 & 45 & & \\
\hline \multirow{2}{*}{ Smoking } & Yes & 4 & 49 & \multirow{2}{*}{0.031} & \multirow{2}{*}{0.861} \\
\hline & No & 1 & 15 & & \\
\hline \multirow{3}{*}{ BMI } & Norm & 1 & 9 & \multirow{3}{*}{1.633} & \multirow{3}{*}{0.442} \\
\hline & Overweight & 4 & 39 & & \\
\hline & Obesity & 0 & 16 & & \\
\hline
\end{tabular}

BMI - body mass index

Table 6. Comparison of groups of patients with and without erectile dysfunction with regard to BDI scores

\begin{tabular}{|c|c|c|c|c|c|}
\hline \multirow{2}{*}{ Parameter } & \multirow{2}{*}{$\begin{array}{l}\text { Distribution } \\
\text { parameter }\end{array}$} & \multicolumn{2}{|c|}{$\begin{array}{c}\text { Erectile } \\
\text { dysfunction }\end{array}$} & \multicolumn{2}{|c|}{ Student's test } \\
\hline & & No & Yes & $t$ & $p$ \\
\hline \multirow{2}{*}{$\begin{array}{l}\text { BDI emotional } \\
\text { subscale }\end{array}$} & Mean & 4.2 & 4.1 & \multirow{2}{*}{0.047} & \multirow{2}{*}{0.923} \\
\hline & $S D$ & 4.2 & 3.6 & & \\
\hline \multirow{2}{*}{ BDI general score } & Mean & 7.2 & 8.0 & \multirow{2}{*}{0.483} & \multirow{2}{*}{0.630} \\
\hline & $S D$ & 6.6 & 5.6 & & \\
\hline
\end{tabular}

BDI - Beck Depression Inventory

Table 7. Comparison of groups of patients with and without erectile dysfunction with regard to diabetes, smoking, and BMI

\begin{tabular}{|l|c|c|c|c|c|}
\hline \multirow{2}{*}{ Risk factor } & \multirow{2}{*}{ Prevalence } & \multicolumn{2}{|c|}{$\begin{array}{c}\text { Erectile } \\
\text { dysfunction }\end{array}$} & \multicolumn{2}{c|}{ Chi-square test } \\
\cline { 3 - 6 } & & Yes & No & $\chi^{2}$ & $p$ \\
\hline \multirow{3}{*}{ Diabetes } & Yes & 19 & 2 & \multirow{2}{*}{4.295} & \multirow{2}{*}{0.038} \\
\cline { 2 - 4 } & No & 32 & 16 & & \\
\hline \multirow{3}{*}{ Smoking } & Yes & 39 & 14 & \multirow{2}{*}{0.013} & \multirow{2}{*}{0.910} \\
\cline { 2 - 5 } & No & 12 & 4 & & \\
\hline \multirow{3}{*}{ BMI } & Norm & 6 & 4 & & \multirow{2}{*}{0.456} \\
\cline { 2 - 4 } & Overweight & 32 & 11 & & \\
\cline { 2 - 4 } & Obesity & 13 & 3 & & \\
\hline
\end{tabular}

BMI - body mass index
The statistical analysis did not show any significant relationship between the presence of mood disorders and risk factors such as diabetes, smoking, and overweight (Table 5).

No significant relationship was observed between the BDI emotional subscale or BDI overall score and ED (Table 6).

The only risk factor significantly correlated with the prevalence of ED was diabetes $(p=0.038)$. Men with ED suffered from diabetes considerably more often than the subjects without this problem. No significant correlation between ED and smoking, overweight, or obesity was found (Table 7).

\section{Discussion}

More and more authors refer to the co-occurrence of conditions like depression, ED, and coronary artery disease as DEC syndrome [28]. Sesso et al. [29] studied a group of 1305 men and described the correlation between coronary artery disease and depression. Valkamoo et al. [30] investigated a group of 144 patients treated for coronary artery disease only and demonstrated the occurrence of depression in $24 \%$ of the subjects. Another research, conducted by Ariyo et al. [31] in a group of 4493 patients presenting severe depression symptoms, confirmed a $40 \%$ increase of the risk of coronary artery disease. In such patients, the risk of death rises by $60 \%$ compared with those without depressive symptoms.

Studies confirming the correlation between the occurrence of ED and depression appeared already in 1998. It turned out that the prevalence of ED was twice higher in patients suffering from depression [32]. In our study, we examined 69 men. Only 5 of them (7.2\%) were diagnosed with mood disorders; $51(73.9 \%)$ reported ED. A very small number of subjects with mood disorders compared with the numerous cases of ED made it impossible to confirm any relationships between depression and ED. There was no statistically significant correlation between declined mood and the occurrence of diabetes, smoking, or excessive body mass.

The only explanation for such a low percentage of depression in our research is the small study group and the resulting limitation in the randomness of the obtained results. Large population studies show that $15-23 \%$ of people with heart diseases - almost twice as many as in the general population - experience depression [33]. A total of $65 \%$ of patients have symptoms of depressed mood immediately after a heart attack. In most cases, these are temporary and disappear within a few days. However, in 16-22\% of individuals, the symptoms are more severe, last longer, and meet the criteria for a moderate or severe depressive episode [34]. Pratt et al. [35] found that the diagnosis of depression in otherwise healthy people increased the risk of a heart attack 4 times. Depression is also a factor raising the risk of cardiovascular complications in people after bypass surgery [33].

Sadness, lack of energy, fear, and anxiety related to depression deprive cardiac patients of their willingness to exercise. A pessimistic attitude towards the future results in their failure to follow the physician's instructions and reluctant participation in rehabilitation, which leads to worsening their health condition, stronger depression, and, subsequently, increased mortality [33, 34].

The research conducted by Walczak et al. [36] in a group of 154 men with ED focused on risk factors such as hypertension, diabetes, smoking, and lipid disorders. Almost half of the participants (40\%) suffered from hypertension, $23 \%$ had diabetes, $17 \%$ were smokers, and $79 \%$ presented elevated BMI. Faselis et al. [37] conducted a study on microvascular complications resulting from type 2 diabetes and confirmed their occurrence leading to ED in up to $90 \%$ of men. Phé and Rou- 
prêt [38] also observed that ED occurred more frequently in men with diabetes. The correlation between ED and endothelium dysfunction caused by diabetes, consequently leading to coronary artery disease, was also established. Our study revealed that diabetes was a significant risk factor of developing ED in men with CVD. Contrary, the correlation between the occurrence of ED and smoking, excess body mass, or depression was not confirmed. However, a small study group may not be a suitable statistical basis for capturing all the relevant relationships.

When speaking of sexual activity, one cannot forget about physical activity, improving sexual performance and preventing $\operatorname{ED}[39,40]$. White et al. [41] confirmed that 9-month training with $80 \%$ of maximal oxygen uptake applied 3 times a week improved the ability to achieve and maintain erection, which affected the frequency of sexual intercourses and the quality of orgasms. The Look AHEAD trial, performed in a group of 373 men aged $45-75$ years, implied that the prevalence of ED decreased by $40 \%$ in individuals doing physical activities as compared with those with sedentary lifestyle [42]. Taking into account that sexual performance is declared by men to be of substantial importance for their quality of life [18], education regarding physical activity and the role that diabetes plays in the occurrence of ED seems to be crucial. It could be a factor making men focus on this health problem and increasing the chance of changing eating habits and lifestyle, especially in patients with heart diseases. Further studies of the issue performed on a much larger scale are still needed.

\section{Conclusions}

The obtained results showed no statistically significant correlation between the occurrence of mood disorders and ED in the studied group of men. The relationship between these two conditions and excessive body weight or smoking has not been confirmed, either. However, these results should be treated with caution owing to the small size of the study group. Only diabetes turned out to be a factor statistically significantly related to the occurrence of ED. Thus, it is not only a serious risk factor for CVD, but also one of the main factors determining the occurrence of ED in cardiac patients.

\section{Disclosure statement}

No author has any financial interest or received any financial benefit from this research.

\section{Conflict of interest}

The authors state no conflict of interest.

\section{References}

1. Strzelecki Z, Szymborski J. Incidence and mortality from cardiovascular diseases and the demographic situation of Poland [in Polish]. Warszawa: Rządowa Rada Ludnościowa; 2015.

2. Zdrojewicz Z, Biega P, Rychter J. Erectile dysfunction and cardiovascular disease [in Polish]. Seksuol Pol. 2013; 11(1):29-39.

3. Deskur-Śmielecka E, Jóźwiak A, Dylewicz P. Cardiac rehabilitation in the elderly [in Polish]. Kardiol Pol. 2008;66: 684-687.

4. Schipper H, Clinch JJ, Olweny CLM. Quality of life studies: definitions and conceptual issues. In: Spilker B (ed.), Quality of life and pharmacoeconomics in clinical trials, $2^{\text {nd }}$ ed. Philadelphia: Lippincott-Raven Publishers; 1996; 11-23.

5. Szyguła-Jurkiewicz B, Kowalska M, Mościński M. Quality tiveness of treatment in patients with cardiovascular diseases [in Polish]. Folia Cardiol Exc. 2011;6(1):62-71.

6. Kustrzycki W, Rymaszewska J, Malcher K, SzczepańskaGieracha J, Biecek P. Risk factors of depressive and anxiety symptoms 8 years after coronary artery bypass grafting. Eur J Cardiothorac Surg. 2012;41(2):302-306; doi: 10.1016/j.ejcts.2011.06.028.

7. Opolski G, Filipiak KJ, Poloński L. Acute coronary syndromes [in Polish]. Wrocław: Urban \& Partner; 2002.

8. Zellweger MJ, Ostewalder RH, Langewitz W, Pfisterer ME. Coronary artery disease and depression. Eur Heart J. 2004;25(1):3-9; doi: 10.1016/j.ehj.2003.09.009.

9. Frasure-Smith N, Lespérance F, Talajic M. Depression following myocardial infarction. Impact on 6-month survival. JAMA. 1993;270(15):1819-1825; doi: 10.1001/jama. 1993.03510150053029.

10. Dudek D, Siwek M. Depression in medical illness [in Polish]. Psychiatria. 2007;4(1):17-24.

11. Dudek D, Siwek M, Datka W, Wróbel A, Zięba A. The evolution of depressive symptoms in coronary artery disease patients after successful coronary angioplasty [in Polish]. Psych Pol. 2007;61(2):217-227.

12. Jastrzębski J. Depression and heart disease [in Polish]. Puls Medycyny. 2008. Available from: https://pulsmedycyny.pl/depresja-a-choroby-serca-881934.

13. Kałka D, Domagała Z, Rusiecki L, Karpiński Ł, Gebala J, Kolęda $P$, et al. Heart rate recovery, cardiac rehabilitation and erectile dysfunction in males with ischaemic heart disease. Anatol J Cardiol. 2016;16(4):256-263; doi: 10.5152/AnatolJCardiol.2015.6122.

14. Szczepańska-Gieracha J, Morka J, Kowalska J, Kustrzycki W, Rymaszewska J. The role of depressive and anxiety symptoms in the evaluation of cardiac rehabilitation efficacy after coronary artery bypass grafting surgery. Eur J Cardiothorac Surg. 2012;42(5):108-114; doi: 10. 1093/ejcts/ezs463.

15. Kubica A. Verification of psychological effects of rehabilitation - the first step to achieve the assumed goals [in Polish]. Folia Cardiol Exc. 2009;4(5):257-259.

16. Kubica A, Bogdan M, Szymański P, Kubica J. The effect of anxiety disorders on sudden cardiac deaths [in Polish]. Psychiatr Prakt Ogólnolek. 2003;3(4):191-195.

17. Mobley DF, Baum N. When patients request the impotence pill: tips for office evaluation and treatment. Postgrad Med. 1998;104(2):55-66; doi: 10.3810/pgm.1998. 08.561.

18. Kałka D, Karpiński $Ł$, Gebala J, Rusiecki L, BiełousWilk A, Krauz ES, et al. Sexual health of male cardiac patients - present status and expectations of patients with coronary heart disease. Arch Med Sci. 2017;13(2):302310; doi:_10.5114/aoms.2017.65332.

19. Lew-Starowicz Z, Filipiak KJ, Januszewicz A, Radziszewski P, Mamcarz A, Lew-Starowicz M, et al. Cardiosexology [in Polish]. Warszawa: Medical Education; 2009.

20. Rasmussen L, Hallas J, Madsen KG, Pottegård A. Cardiovascular drugs and erectile dysfunction - a symmetry analysis. Br J Clin Pharmacol. 2015;80(5):1219-1223; doi: $10.1111 /$ bcb.12696.

21. Woroń J, Kostka-Trąbka E. The erectile dysfunction as a effect of adverse drug reactions [in Polish]. Seksuol Pol. 2005;3(1):18-22.

22. Izdebski Z. Report 'A study on the sexuality of people aged over 50' [in Polish]. Warszawa, Zielona Góra; 2007.

23. Sochaj M. Risk factors for erectile dysfunction [in Polish]. Adv Androl Online. 2019;6(1):40-50; doi: 10.26404/PAO _2353-8791.2019.03. 
24. Rabijewski M, Papierska L. Pathogenesis and treatment of erectile dysfunction [in Polish]. Geriatr Pol. 2007;1: 203-208.

25. Kałucka S. Characteristics of depression in the elderly - etiology, diagnosis and treatment [in Polish]. Geriatria. 2014;8:240-247.

26. Beck AT, Ward CH, Mendelson M, Mock J, Erbaugh J. An inventory for measuring depression. Arch Gen Psychiatry. 1961;4:561-571; doi: 10.1001/archpsyc.1961. 01710120031004.

27. Rosen RC, Cappelleri JC, Smith MD, Lipsky J, Peña BM. Development and evaluation of an abridged, 5-item version of the International Index of Erectile Function (IIEF-5) as a diagnostic tool for erectile dysfunction. Int $\mathrm{J}$ Impot Res. 1999;11(6):319-326; doi: 10.1038/sj.ijir.3900472.

28. Kopka M, Kotowicz J. DEC (depression, erection dysfunction, coronary artery disease) syndrome: underdiagnosed triad [in Polish]. Pol Przegl Med Lotn. 2008;14(3): 269-276.

29. Sesso HD, Kawachi I, Vokonas PS, Sparrow D. Depression and the risk of coronary heart disease in the normative aging study. Am J Cardiol. 1998;82(7):851-856; doi: 10.1016/s0002-9149(98)00491-3.

30. Valkamo M, Hintikka J, Niskanen L, Koivumaa-Hounkanen $\mathrm{H}-\mathrm{T}$, Honkalampi K, Viinamäki H. Depression and associated factors in coronary heart disease. Scand Cardiovasc J. 2001;35(4):259-263; doi: 10.1080/14017430 152581378.

31. Ariyo AA, Haan M, Tangen CM, Rutledge JC, Cushman M, Dobs A, et al. Depressive symptoms and risks of coronary heart disease and mortality in elderly Americans. Circulation. 200;102(15):1773-1779; doi: 10.1161/01. cir.102.15.1773.

32. Araujo AB, Durante R, Feldman HA, Goldstein I, McKinlay JB. The relationship between depressive symptoms and male erectile dysfunction: cross-sectional results from the Massachusetts Male Aging Study. Psychosom Med. 1998;60(4):458-465; doi: 10.1097/00006842-19 9807000-00011.

33. Krupka-Matuszczyk I. Depression in heart disease [in Polish]. Kardiol Dypl. 2012;11(3):57-61.

34. Szyguła-Jurkiewicz B, Szymik M, Mrozowska B, Schmidt B, Michalak A. Psychological consequences of acute myocardial infraction. Psychotropic drugs in patients after acute myocardial infarction [in Polish]. Chor Serca Naczyn. 2011;8(2):62-69.

35. Pratt LA, Ford DE, Crum RM, Armenian HK, Gallo JJ, Eaton WW. Depression, psychotropic medication, and risk of myocardial infarction. Prospective data from the Baltimore ECA follow-up. Circulation. 1996;94(12):3123 -3129; doi: 10.1161/01.cir.94.12.3123.

36. Walczak MK, Lokhandwala N, Hodge MB, Guay AT. Prevalence of cardiovascular risk factors in erectile dysfunction. J Gend Specif Med. 2002;5(6):19-24.

37. Faselis C, Katsimardou A, Imprialos K, Deligkaris $P$, Kallistratos M, Dimitriadis K. Microvascular complications of type 2 diabetes mellitus. Curr Vasc Pharmacol. 2020; 18(2):117-124; doi: 10.2174/157016111766619050210 3733.

38. Phé V, Rouprêt M. Erectile dysfunction and diabetes: a review of the current evidence-based medicine and a synthesis of the main available therapies. Diabetes Metab. 2012;38(1):1-13; doi: 10.1016/j.diabet.2011.09. 003.

39. Bacon CG, Mittleman MA, Kawachi I, Giovannucci E, Glasser DB, Rimm EB. Sexual function in men older than
50 years of age: results from the health professionals follow-up study. Ann Intern Med. 2003;139(3):161-168; doi: 10.7326/0003-4819-139-3-200308050-00005.

40. Esposito K, Giugliano F, Di Palo C, Giugliano G, Marfella R, D'Andrea F, et al. Effect of lifestyle changes on erectile dysfunction in obese men: a randomized controlled trial. JAMA. 2004;291(24):2978-2984; doi: 10.1001/jama. 291.24.2978.

41. White JR, Case DA, McWhirter D, Mattison AM. Enhanced sexual behavior in exercising men. Arch Sex Behav. 1990;19(3):193-209; doi: 10.1007/bf01541546.

42. Rosen RC, Wing RR, Schneider S, Wadden TA, Foster GD, West DS, et al. Erectile dysfunction in type 2 diabetic men: relationship to exercise fitness and cardiovascular risk factors in the Look AHEAD trial. J Sex Med. 2009;6(5):1414-1422; doi: 10.1111/j.1743-6109.2008. 01209.x. 